\title{
Involvement of sphingosine 1-phosphate in palmitate-induced insulin resistance of hepatocytes via the $\mathrm{S}_{1} \mathrm{P}_{2}$ receptor subtype
}

\author{
Susann Fayyaz • Janin Henkel • Lukasz Japtok • \\ Stephanie Krämer • Georg Damm • Daniel Seehofer • \\ Gerhard P. Püschel • Burkhard Kleuser
}

Received: 10 October 2013 / Accepted: 6 November 2013 / Published online: 29 November 2013

(C) Springer-Verlag Berlin Heidelberg 2013

\begin{abstract}
Aims/hypothesis Enhanced plasma levels of NEFA have been shown to induce hepatic insulin resistance, which contributes to the development of type 2 diabetes. Indeed, sphingolipids can be formed via a de novo pathway from the saturated fatty acid palmitate and the amino acid serine. Besides ceramides, sphingosine 1-phosphate (S1P) has been identified as a major bioactive lipid mediator. Therefore, our aim was to investigate the generation and function of S1P in hepatic insulin resistance.

Methods The incorporation of palmitate into sphingolipids was performed by rapid-resolution liquid chromatographyMS/MS in primary human and rat hepatocytes. The influence of S1P and the involvement of S1P receptors in hepatic insulin
\end{abstract}

Susann Fayyaz and Janin Henkel contributed equally to this work.

Electronic supplementary material The online version of this article (doi:10.1007/s00125-013-3123-6) contains peer-reviewed but unedited supplementary material, which is available to authorised users.

\footnotetext{
S. Fayyaz $\cdot$ L. Japtok $\cdot$ B. Kleuser $(\bowtie)$

Faculty of Mathematics and Natural Science, Institute of Nutritional

Science, Department of Toxicology, University of Potsdam,

Arthur-Scheunert Allee 114-116, 14558 Nuthetal, Potsdam,

Germany

e-mail: kleuser@uni-potsdam.de

J. Henkel · G. P. Püschel

Faculty of Mathematics and Natural Science, Institute of Nutritional

Science, Department of Nutritional Biochemistry, University of

Potsdam, Potsdam, Germany

S. Krämer

Max Rubner Laboratory, German Institute of Human Nutrition,

Nuthetal, Germany

G. Damm • D. Seehofer

Department of General-, Visceral- and Transplantation Surgery,

Charité University of Medicine Berlin, Berlin, Germany
}

resistance was examined in human and rat hepatocytes, as well as in New Zealand obese (NZO) mice.

Results Palmitate induced an impressive formation of extraand intracellular S1P in rat and human hepatocytes. An elevation of hepatic S1P levels was observed in NZO mice fed a high-fat diet. Once generated, S1P was able, similarly to palmitate, to counteract insulin signalling. The inhibitory effect of S1P was abolished in the presence of the $\mathrm{S}_{1} \mathrm{P}_{2}$ receptor antagonist JTE-013 both in vitro and in vivo. In agreement with this, the immunomodulator FTY720-phosphate, which binds to all $\mathrm{S} 1 \mathrm{P}$ receptors except $\mathrm{S}_{1} \mathrm{P}_{2}$, was not able to inhibit insulin signalling.

Conclusions/interpretation These data indicate that palmitate is metabolised by hepatocytes to S1P, which acts via stimulation of the $\mathrm{S}_{1} \mathrm{P}_{2}$ receptor to impair insulin signalling. In particular, $\mathrm{S}_{1} \mathrm{P}_{2}$ inhibition could be considered as a novel therapeutic target for the treatment of insulin resistance.

Keywords FTY720 $\cdot$ Insulin signalling $\cdot$ Palmitate $\cdot$ S1P receptors $\cdot$ Sphingolipids $\cdot$ Sphingosine 1-phosphate

\begin{tabular}{ll}
\multicolumn{2}{l}{ Abbreviation } \\
ABC & ATP-binding cassette \\
DAG & Diacylglycerol \\
FTY720-P & FTY720-phosphate \\
GPCR & G protein-coupled receptor \\
GSK-3 $\beta$ & Glycogen synthase kinase-3 $\beta$ \\
HFD & High-fat diet \\
HRP & Horseradish peroxidase \\
NZO & New Zealand obese \\
PI $_{3} K$ & Phosphatidylinositide 3-kinase \\
PKC & Protein kinase C \\
S1P & Sphingosine 1-phosphate \\
SD & Standard diet \\
SKII & Sphingosine kinase inhibitor 2 \\
Sphk & Sphingosine kinase
\end{tabular}




\section{Introduction}

Enhanced circulating levels of NEFA have been indicated to induce hepatic insulin resistance [1], which is a major risk factor for the development of type 2 diabetes [2]. Hepatic insulin resistance is defined clinically in terms of a failure of insulin to maintain glucose homeostasis, leading to hyperglycaemia. Unrestrained hepatic glucose production is a consequence of a reduced efficacy of insulin to suppress hepatic gluconeogenesis and glycogenolysis, while reduced hepatic glucose clearance results from an impaired insulindependent stimulation of glycogen synthesis [3].

Insulin receptor downstream signalling has been extensively examined in an attempt to discover the molecular alterations induced by NEFA. One major branch of intracellular insulin signalling is the activation of the phosphatidylinositide 3-kinase $\left(\mathrm{PI}_{3} \mathrm{~K}\right) /$ Akt pathway, which mediates most of its metabolic effects. Thus, stimulation of the $\mathrm{PI}_{3} \mathrm{~K} /$ Akt pathway directly induces the phosphorylation and subsequent inactivation of glycogen synthase kinase-3 $\beta$ (GSK-3 $\beta$ ), which in turn phosphorylates and inactivates glycogen synthase [4]. Moreover, $\mathrm{PI}_{3} \mathrm{~K} / \mathrm{Akt}$ activation is involved in the modulation of glucokinase levels and hence activity [5]. Both enhanced glucokinase activity and inactivation of GSK-3 $\beta$ in response to insulin contribute to enhanced glycogen synthesis. Exposure of hepatic cells to NEFA interrupts insulin signalling by inhibiting the $\mathrm{PI}_{3} \mathrm{~K} / \mathrm{Akt}$ pathway, but the relative contribution of the different potential mechanisms is still a matter of debate.

An accumulation of NEFA in the liver results in oxidative stress, local inflammation and cytokine production [6]. Moreover, bioactive lipid intermediates such as diacylglycerol (DAG) appear to accumulate in response to NEFA. Hepatic DAG formation is thought to stimulate classical and atypical protein kinase $\mathrm{C}(\mathrm{PKC})$ isoforms, which blunt insulin signalling by inactivation of the insulin receptor substrate [7]. Of note, saturated and unsaturated fatty acids differ significantly in their participation in inducing insulin resistance, suggesting the formation of further specific bioactive lipids depending on the individual fatty acids [8]. Thus, ceramides, which can be formed by a de novo pathway from the saturated fatty acid palmitate, have been indicated as interrupting several putative targets of insulin signalling [9]. For instance, ceramides directly activate a $\mathrm{PKC} \zeta$ isoform that inhibits the translocation of Akt. Additionally ceramides stimulate the activity of cytosolic protein phosphatase, which accounts for the dephosphorylation of Akt [10].

Once generated, ceramides can be further metabolised to a large array of bioactive sphingolipid metabolites. For example, ceramides can be hydrolysed by ceramidase to sphingosine, which can in turn be phosphorylated to sphingosine 1-phosphate (S1P) by sphingosine kinase (Sphk) [11]. S1P is a potent signal mediator that affects multiple cellular functions. The multitude of different S1P-mediated actions can be explained by the fact that the sphingolipid on the one hand possesses intracellular targets and on the other hand acts as a ligand of the G protein-coupled receptor (GPCR) after secretion into the extracellular environment. Five high-affinity receptors for $\mathrm{S} 1 \mathrm{P}$, designated $\mathrm{S}_{1} \mathrm{P}_{1}-\mathrm{S}_{1} \mathrm{P}_{5}$, have so far been identified [12]. S1P has been shown to increase glucose uptake into skeletal muscle via transactivation of the insulin receptor [13]. In contrast, S1P interrupted insulin signalling in epithelial cells via an inhibition of Akt activity [14]. Since S1P, depending on the tissue analysed, may apparently affect glucose and lipid metabolism in different ways, the aim of this study was to examine whether palmitate contributes to the formation of S1P, which may affect hepatic insulin signalling.

\section{Methods}

Materials Narcoreen was purchased from Merial (Hallbergmoos, Germany). Percoll and $D-\left[\mathrm{U}-{ }^{14} \mathrm{C}\right]$ glucose were obtained from GE Healthcare (Freiburg, Germany). S1P was synthesised as described [15]. C17-S1P came from Avanti Polar Lipids (Alabaster, AL, USA). FTY720-phosphate (FTY720-P) and JTE-013 were obtained from Cayman (Hamburg, Germany). Sphk inhibitor 2 (SKII), monoclonal rabbit anti-phospho $\mathrm{Akt}^{\mathrm{Ser} 473}$ antibody, monoclonal anti-total Akt antibody, monoclonal rabbit anti-phospho GSK-3 $\beta^{\text {Ser9 }}$ antibody, rabbit monoclonal anti-GSK-3 $\beta$ antibody, secondary anti-rabbit IgG horseradish peroxidase (HRP)-linked antibody as well as LumiGLO reagent and peroxide chemiluminescent substrate were obtained from Cell Signaling Technology (Frankfurt, Germany). Primers were synthesised by Eurofins MWG Operon (Ebersberg, Germany). All other chemicals were purchased from Sigma-Aldrich (Schnelldorf, Germany).

Experimental animals Male Wistar rats (200-300 g) were purchased from Charles River (Sulzfeld, Germany). Male New Zealand obese (NZO) mice (28-35 g) were bred inhouse in the animal facility of the German Institute of Human Nutrition (Nuthetal, Germany) and housed in groups (three-five animals per cage) under standard laboratory housing conditions with a diurnal $12 \mathrm{~h}$ light and dark cycle. The animals had free access to fresh tap water and food, and were kept in accordance with relevant national and international guidelines. The local authorities approved all the animal experiments (LUGV Brandenburg, Germany; V3-2347-3-2012).

Study design The mice $(n=15)$ were randomised into three study groups receiving a standard diet (SD), a high-fat diet (HFD) or an HFD plus JTE-013. All the diets were purchased from Altromin (Lage, Germany). The SD (Art. No. C1090-10) contained (wt/wt) $10 \mathrm{~kJ} \%$ fat, and the HFD (Art. No. C109060 ) contained $(\mathrm{wt} / \mathrm{wt}) 60 \mathrm{~kJ} \%$ fat. The dietary intervention was started at 6 weeks of age and was continued for 4 weeks. When hyperglycaemia (blood glucose level over $20 \mathrm{mmol} / \mathrm{l}$ ) occurred 
in week 3 in the HFD groups, JTE-013 intervention was initiated and applied for 7 days. JTE-013 (3 mg/ $\mathrm{kg}$ ) was dissolved in PBS containing DMSO (5\%) and BSA (3\%) and administered by i.p. injection. The control animals received the vehicle. Samples for measuring blood glucose were collected from the tail vein of fed mice between 09:00 and 11:00. Blood glucose was determined using an Ascensia ELITE XL (Bayer HealthCare, Leverkusen, Germany). At the end of the experiment, the mice were fasted overnight for $14 \mathrm{~h}$. All the mice received an i.p. injection of insulin ( $2 \mathrm{mU} / \mathrm{kg}$ ). Isoflurane anaesthesia was induced $15 \mathrm{~min}$ later and $1 \mathrm{ml}$ of blood was withdrawn by cardiac puncture. The animals were killed by cervical dislocation, and the liver was harvested for further investigations.

Preparation and cultivation of primary rat hepatocytes Density gradient-purified hepatocytes were prepared and cultured as previously described [16]. The cells were plated on $35 \mathrm{~mm}$ diameter culture plates $\left(1 \times 10^{6}\right.$ cells/plate), and experimental treatments were performed after 24 or $44 \mathrm{~h}$ [17].

Preparation and cultivation of primary human hepatocytes Tissue samples from liver resections were obtained from patients undergoing partial hepatectomy. The experimental procedures were performed according to the guidelines of the charitable state-controlled foundation Human Tissue and Cell Research, with the informed patient's consent approved by the local Ethical Committee of the Charité University of Medicine Berlin (EA2/076/09). The cell isolation process was performed using a two-step collagenase $\mathrm{P}$ perfusion technique [18]. Isolated hepatocytes were cultured in Williams' medium E containing $10 \% \mathrm{FCS}$, insulin $(1 \mu \mathrm{mol} / \mathrm{l})$, HEPES $(15 \mathrm{mmol} / \mathrm{l})$, dexamethasone $(100 \mathrm{nmol} / \mathrm{l}), 100 \mathrm{U} / \mathrm{ml}$ penicillin and $100 \mu \mathrm{g} / \mathrm{ml}$ streptomycin, $1 \% \mathrm{~L}$-glutamine, $1 \%$ non-essential amino acids and sodium pyruvate $(1 \mathrm{mmol} / \mathrm{l})$ overnight on collagen-coated culture plates $\left(1 \times 10^{6}\right.$ cells/plate). After an initial $12 \mathrm{~h}$ incubation to allow the cells to attach to the substratum, the medium was changed to Williams' medium E $1 \%$ (vol./vol.), antibiotics (10 U/ $\mu \mathrm{g}$ penicillin, $10 \mu \mathrm{g} / \mu \mathrm{l}$ streptomycin), dexamethasone $(100 \mathrm{nmol} / \mathrm{l})$ and insulin $(0.5 \mathrm{nmol} / \mathrm{l})$ without FCS. Experimental treatments were performed after $44 \mathrm{~h}$ of culture in Williams' medium E containing 1\% (vol./vol.) antibiotics and dexamethasone $(100 \mathrm{nmol} / \mathrm{l})$.

Sphingolipid quantification Ceramides and S1P were extracted and quantified as recently described [19, 20]. Briefly, lipid extraction of tissue samples, primary hepatocytes or conditioned cell media was performed using C17-S1P and C17-ceramide as internal standards. Sample analysis was carried out by rapid-resolution liquid chromatography-MS/ MS using a Q-TOF 6530 mass spectrometer (Agilent Technologies, Waldbronn, Germany) operating in the positive ESI mode. The precursor ions of S1P (m/z 380.256), C17-S1P (m/z 366.240), C16-ceramide (m/z 520.508) and C17ceramide $(\mathrm{m} / \mathrm{z} 534.524)$ were cleaved into the fragment ions of $\mathrm{m} / \mathrm{z} 264.270, \mathrm{~m} / \mathrm{z} 250.252, \mathrm{~m} / \mathrm{z} 264.270$ and $\mathrm{m} / \mathrm{z} 264.270$ respectively. Quantification was performed with Mass Hunter Software (Agilent Technologies).

RT-PCR Total RNA was isolated using the total RNA isolation system (Roboklon, Berlin, Germany). The RT reaction was carried out using the FermentasAid first-strand cDNA synthesis kit (Fermentas, St Leon-Rot, Germany). A volume of $50 \mathrm{ng}$ cDNA solution was subjected to quantitative realtime PCR using a LightCycler480 and the SYBR-Green PCR master mix (Roche Diagnostics, Applied Science, Mannheim, Germany). $\beta$-Actin or GAPDH was used as normalisation control. The primers used in this study are shown in electronic supplementary material (ESM) Table 1.

$D-\left[U_{-}{ }^{14} C\right]$ glucose incorporation into glycogen Glycogen synthesis was assessed by measuring $D-\left[\mathrm{U}_{-}{ }^{14} \mathrm{C}\right]$ glucose incorporation into glycogen as recently described [17]. Briefly, cultured hepatocytes were preincubated for $5 \mathrm{~h}$ with $1 \mu \mathrm{mol} / 1$ S1P in M199 medium containing 1\% penicillin/streptomycin and dexamethasone $(100 \mathrm{nmol} / \mathrm{l})$. Subsequently, the medium was replaced by medium containing $1 \mu \mathrm{Ci} / \mathrm{ml} D$-[U- $\left.{ }^{14} \mathrm{C}\right]$ glucose and after $30 \mathrm{~min}$ hepatocytes were stimulated with insulin $(10 \mathrm{nmol} / \mathrm{l})$ for $2 \mathrm{~h}$. Glycogen was precipitated and the amount of $D-\left[\mathrm{U}-{ }^{14} \mathrm{C}\right]$ glycogen was determined by scintillation counting.

Immunoblotting Western blot analysis was performed as recently described [21]. Briefly, cells or tissue samples were lysed in radioimmunoprecipitation assay buffer and lysates were centrifuged and boiled in SDS sample buffer. After separation by SDS-PAGE, gels were blotted onto polyvinylidene fluoride membranes and blocked with non-fat dry milk. Membranes were incubated with the primary antibodies followed by incubation with secondary anti-rabbit IgG HRP-linked antibodies. Detection was performed with LumiGLO according to the manufacturer's protocol using a ChemiDoc XRS+ system (Bio-Rad Laboratories, Munich, Germany).

Statistical analyses Data are expressed as the mean \pm SEM of results of three or more independent experiments. Statistical analyses ( $t$ tests) were performed using GraphPad Prism 6.0 software (GraphPad Software, La Jolla, CA, US). Values of ${ }^{*} p<0.05$ and ${ }^{* *} p<0.01$ indicate a statistically significant difference vs control experiments.

\section{Results}

Palmitate induces the formation of S1P in rat hepatocytes An examination of palmitate incorporation into sphingolipids in 


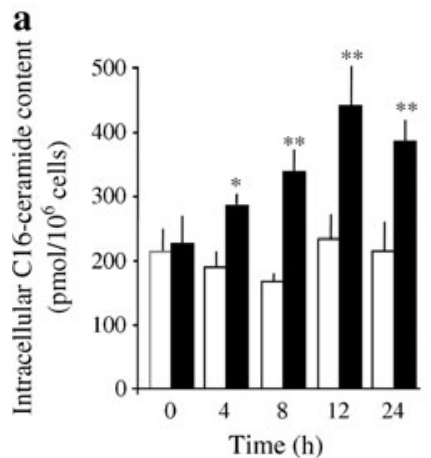

b

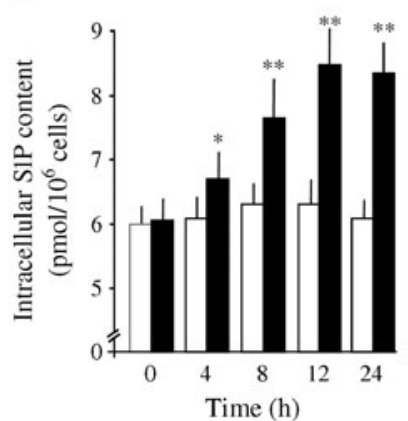

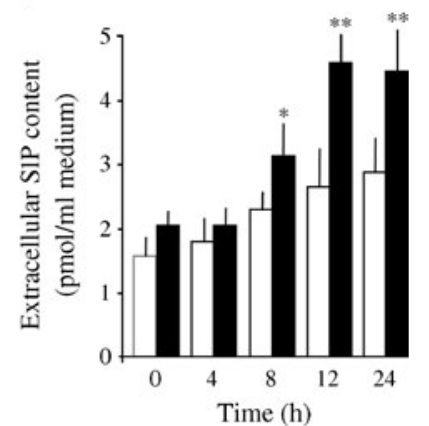

Fig. 1 Formation of C16-ceramide and S1P in response to palmitate. Rat hepatocytes were isolated and cultured as described in Methods. After $44 \mathrm{~h}$ of culture, the cells were treated with vehicle (white bars) or $0.3 \mathrm{mmol} / 1$ palmitate (black bars) for the indicated time periods. Levels of C16-ceramide (a) and S1P (b) were determined in hepatocytes, as was

primary rat hepatocytes revealed that there was a significant increase in the formation of sphingolipids. Exposing primary rat hepatocytes to palmitate $(0.3 \mathrm{mmol} / \mathrm{l})$ over a time period of $24 \mathrm{~h}$ induced not only an intracellular formation of C16-ceramide (Fig. 1a) but also an intracellular increase in the further metabolite S1P (Fig. 1b). A significant enhancement of both C16-ceramide and S1P levels in response to
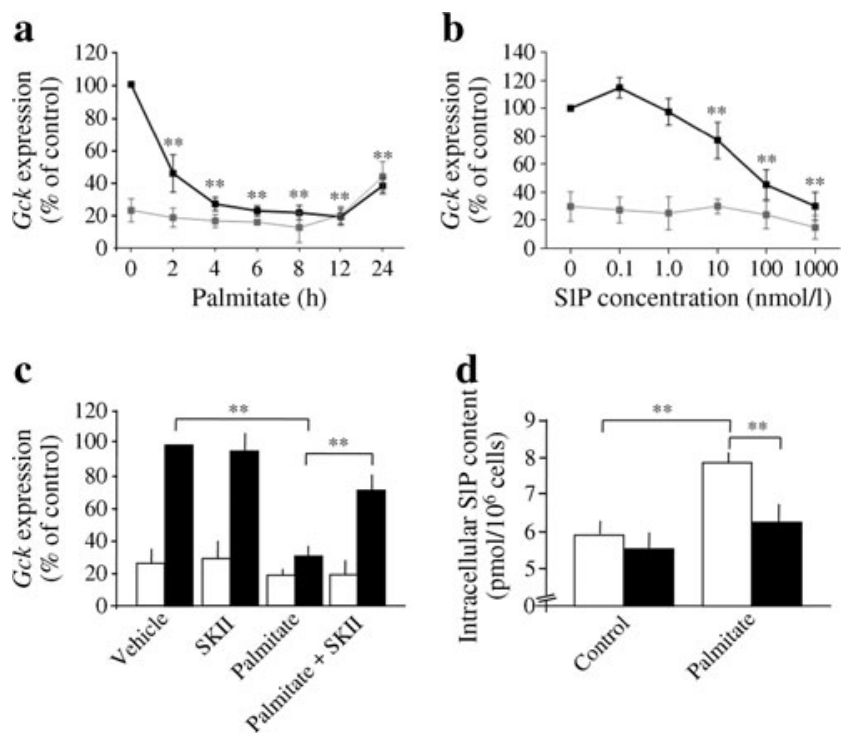

Fig. 2 Participation of S1P in palmitate-mediated inhibition of glucokinase $(G c k)$ expression. Rat hepatocytes were isolated and cultured for $44 \mathrm{~h}$. The cells were then preincubated with vehicle, palmitate $(0.3 \mathrm{mmol} / \mathrm{l})$ for the indicated time periods (a) or S1P in the indicated concentrations for $5 \mathrm{~h}$ (b). To inhibit Sphk1, cells were cultured for $24 \mathrm{~h}$ and preincubated with vehicle or SKII $(1 \mu \mathrm{mol} / \mathrm{l})$ for $12 \mathrm{~h}$ followed by incubation with palmitate for $12 \mathrm{~h} \mathrm{(c).} \mathrm{The} \mathrm{hepatocytes} \mathrm{were} \mathrm{then} \mathrm{stimulated} \mathrm{with} \mathrm{vehicle}$ (grey lines, white bars) or $10 \mathrm{nmol} / \mathrm{l}$ insulin (black lines, black bars) for $2 \mathrm{~h}$. The glucokinase mRNA level in insulin-treated hepatocytes preincubated with vehicle was set to $100 \%$ (control). S1P levels in response to palmitate were quantified after treatment of the hepatocytes with vehicle (white bars) or the Sphk1 inhibitor SKII (black bars) by MS/MS-QTOF analysis (d). Values are the means \pm SEM of five independent experiments. ${ }^{* *} p<0.01$ indicates a statistically significant difference the release of S1P into the medium (c) by liquid chromatography-MS/ MS-QTOF analysis. Data are expressed as the mean \pm SEM of the results from five independent experiments. ${ }^{*} p<0.05$ and ${ }^{* *} p<0.01$ indicate a statistically significant difference vs experiments with vehicle stimulation
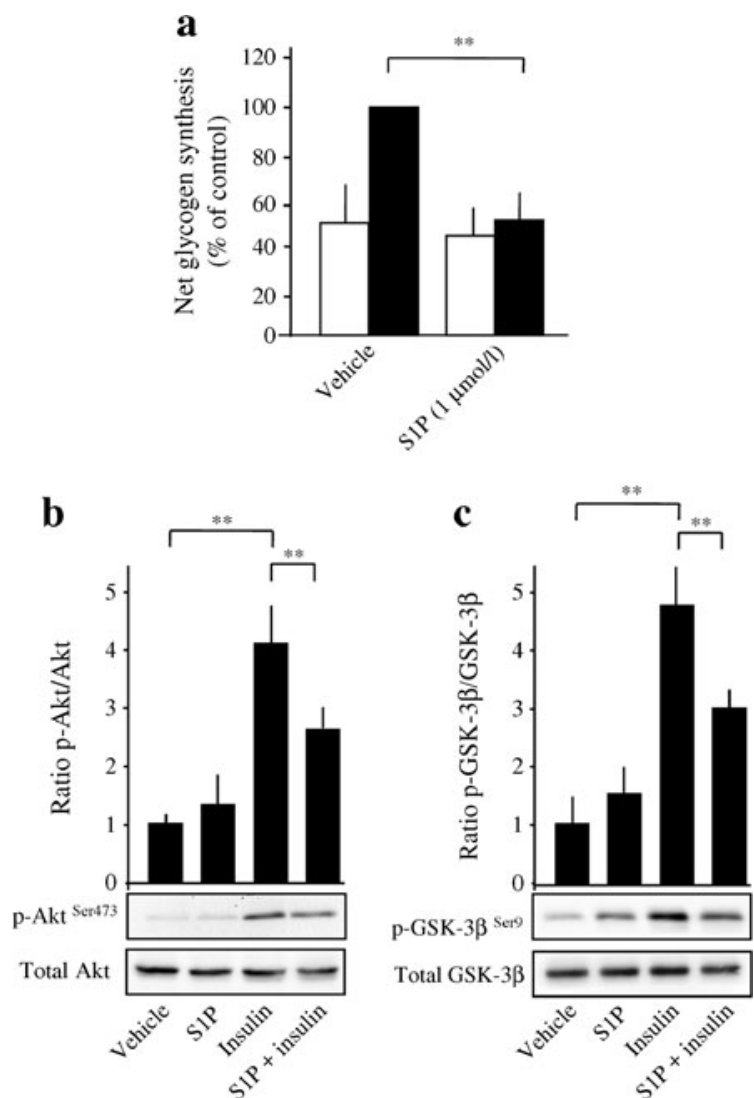

Fig. 3 Influence of S1P on insulin signalling in primary rat hepatocytes. Cells were isolated and cultured for $44 \mathrm{~h}$. For glycogen synthesis, cells were preincubated with vehicle or $\operatorname{S1P}(1 \mu \mathrm{mol} / \mathrm{l})$ for $5 \mathrm{~h}$. The hepatocytes were then stimulated with vehicle (white bars) or $10 \mathrm{nmol} / \mathrm{l}$ insulin (black bars) for $2 \mathrm{~h}$. Glycogen synthesis in insulin-treated hepatocytes preincubated with vehicle was set to $100 \%$ (control) (a). For western blot analysis, hepatocytes were treated with $\mathrm{S} 1 \mathrm{P}(1 \mu \mathrm{mol} / \mathrm{l})$ for $15 \mathrm{~min}$ followed by stimulation with insulin $(10 \mathrm{nmol} / \mathrm{l})$ for $10 \mathrm{~min}$. The phosphorylation of Akt (b) and GSK-3 $\beta$ (c) was determined. Values from the western blot analysis are expressed as fold increases compared with the nonphosphorylated control and are the means \pm SEM of four independent experiments. ${ }^{* *} p<0.01$ indicates a statistically significant difference 
palmitate was detectable after a stimulation period of $4 \mathrm{~h}$. Maximum concentrations of these sphingolipids were reached at $12 \mathrm{~h}$. At this incubation time, the C16-ceramide concentration increased from a basal level of approximately 210 to $450 \mathrm{pmol} / 10^{6}$ cells, whereas the S1P level was enhanced from 6.0 to $8.6 \mathrm{pmol} / 10^{6}$ cells in response to palmitate.

To analyse whether S1P is also secreted into the extracellular environment, levels of S1P were determined in the supernatant fraction of cultured hepatocytes. A basal level of $1.5 \mathrm{pmol}$ could be detected in $1 \mathrm{ml}$ of medium, indicating that the hepatocytes produced and released endogenous S1P. Most interestingly, a strong increase in S1P in the extracellular environment occurred in the presence of palmitate. After $8 \mathrm{~h}$, the S1P concentration was already significantly higher than in the respective controls. Maximum S1P levels were detected after $12 \mathrm{~h}$ of palmitate exposure. Thus, the S1P level increased approximately 2.5 -fold from 1.7 to $4.4 \mathrm{pmol} / 1 \mathrm{ml}$ medium (Fig. 1c).

\section{Participation of S1P on palmitate-mediated inhibition of glu-} cokinase levels It is well known that palmitate plays a central role in hepatic insulin resistance. As the S1P level increased in response to palmitate, the influence of both palmitate and S1P on insulin-mediated levels of glucokinase, a rate-controlling enzyme for hepatic glycogen synthesis, was examined in primary rat hepatocytes. An approximately fivefold induction of glucokinase was seen when the cells were stimulated with insulin $(10 \mathrm{nmol} / \mathrm{l})$ for $2 \mathrm{~h}$ (Fig. 2a, b). However, preincubation with palmitate reduced the insulin-dependent glucokinase induction in a time-dependent manner with a maximum reduction after $12 \mathrm{~h}$ (Fig. 2a). This coincided with the maximum palmitate-induced generation of S1P. Therefore, the role of S1P in glucokinase levels was examined. Similarly to palmitate, S1P attenuated the insulindependent induction of glucokinase. The inhibitory effect of S1P was dose dependent with a significant reduction in the insulin-induced expression of glucokinase at a concentration of $100 \mathrm{nmol} / \mathrm{l}$, whereas a maximum inhibition occurred at $1 \mu \mathrm{mol} / \mathrm{l}$ of S1P (Fig. 2b).

To prove an involvement of S1P generation in the inhibitory action of palmitate on insulin signalling, glucokinase levels were measured in the presence of SKII. As expected, SKII diminished the ability of palmitate to increase S1P levels (Fig. 2d). The inhibitory action of palmitate on insulininduced glucokinase levels was also significantly decreased in the presence of SKII (Fig. 2c). These results indicate that the formation of S1P in response to palmitate contributes at least in part to the inhibitory action on insulin signalling.

S1P reduces insulin-mediated glycogen synthesis and Akt and GSK-3 $\beta$ activation To study the biological consequences of an S1P-mediated inhibition of insulin-induced glucokinase levels, hepatic glycogen synthesis was examined. In accordance with its effect on glucokinase levels, insulin $(10 \mathrm{nmol} / \mathrm{l})$ increased the incorporation of radiolabelled glucose into glycogen about twofold. However, when hepatocytes were preincubated with S1P (Fig. 3a), insulin almost completely lost its ability to stimulate glycogen synthesis, confirming the crucial role of S1P in hepatic insulin signalling. It is well known that glucokinase expression and glycogen synthesis occurs in response to insulin, at least in part, downstream of the $\mathrm{PI}_{3} \mathrm{~K} /$ Akt-pathway. Consequently, activation of $\mathrm{PI}_{3} \mathrm{~K} / \mathrm{Akt}$
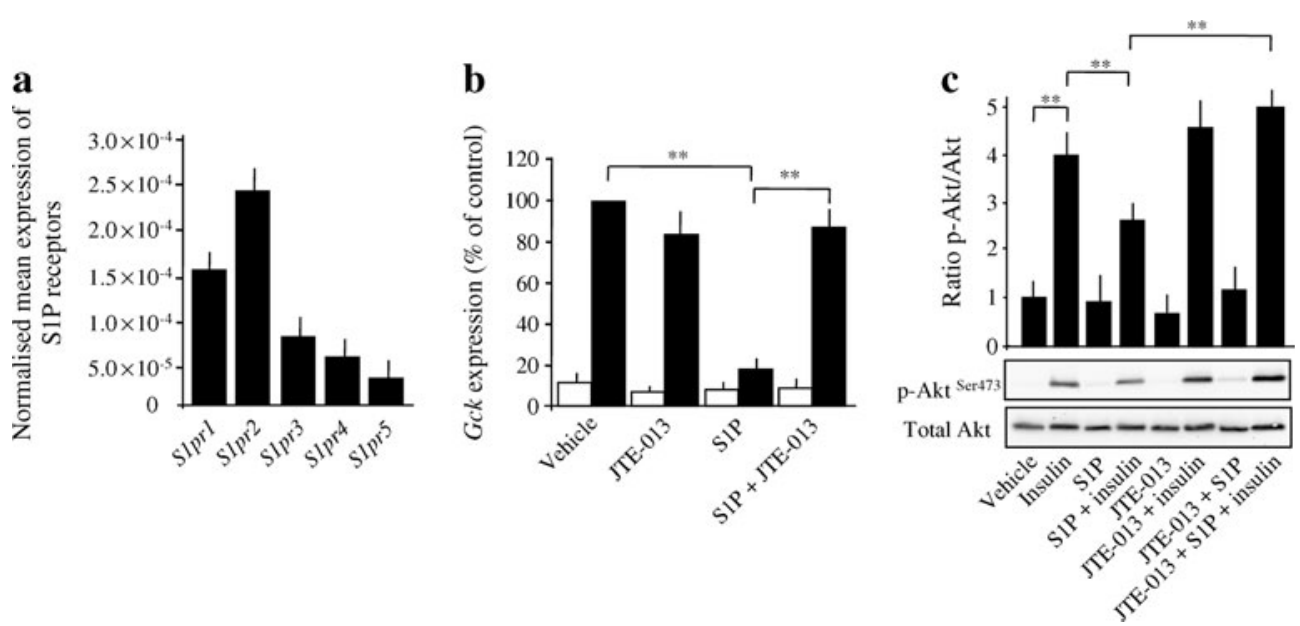

Fig. 4 Involvement of the $\mathrm{S}_{1} \mathrm{P}_{2}$ receptor subtype in the S1P-mediated attenuation of insulin signalling. Quantitative real-time PCR analysis of the S1P receptor subtypes S1pr1, S1pr2, S1pr3, S1pr4 and S1pr5 in rat hepatocytes was performed using $\beta$-actin as a reference gene (a). To measure glucokinase mRNA (Gck), cells were preincubated with JTE$013(10 \mu \mathrm{mol} / \mathrm{l})$ for $30 \mathrm{~min}$ followed by stimulation with vehicle or S1P $(1 \mu \mathrm{mol} / \mathrm{l})$ for $5 \mathrm{~h}$ and by stimulation with vehicle (white bars) or $10 \mathrm{nmol} / \mathrm{l}$ insulin (black bars) for $2 \mathrm{~h}$. The glucokinase mRNA level in insulin- treated hepatocytes preincubated with vehicle was set to $100 \%$ (control) (b). To determine the level of phosphorylated Akt, cells were preincubated with JTE-013 $(10 \mu \mathrm{mol} / \mathrm{l})$ for $30 \mathrm{~min}$ followed by stimulation with vehicle or S1P $(1 \mu \mathrm{mol} / \mathrm{l})$ for $15 \mathrm{~min}$ and insulin $(10 \mathrm{nmol} / \mathrm{l})$ for $10 \mathrm{~min}$. Phosphorylation of Akt was determined by western blot analysis and the data expressed as fold increases compared with non-phosphorylated control (c). Values are the means \pm SEM of four independent experiments. ${ }^{* *} p<0.01$ indicates a statistically significant difference 
in response to insulin and S1P was studied. Pretreatment of hepatocytes with S1P reduced the ability of insulin to induce Akt phosphorylation of $\mathrm{Ser}^{473}$. A maximum reduction was visible after a preincubation time of $15 \mathrm{~min}$ with $1 \mu \mathrm{mol} / \mathrm{l}$ of $\mathrm{S} 1 \mathrm{P}$ (Fig. 3b). Moreover, $\mathrm{PI}_{3} \mathrm{~K} / \mathrm{Akt}$ contributes to the phosphorylation of GSK-3 $\beta$, a direct inactivator of glycogen synthase. In accordance with an inhibitory effect on $\mathrm{PI}_{3} \mathrm{~K} / \mathrm{Akt}$, a 15 min pretreatment of hepatocytes with S1P $(1 \mu \mathrm{mol} / \mathrm{l})$ resulted in a considerable inhibition of the insulin-mediated phosphorylation of the downstream target GSK-3 $\beta$ (Fig. 3c).

S1P inhibits insulin-stimulated glucokinase levels via the $\mathrm{S}_{2} \mathrm{P}_{2}$ receptor subtype As S1P acts as both an extracellular ligand for cell surface receptors and an intracellular signalling molecule, the levels of S1P receptor subtypes in rat hepatocytes were measured. Real-time PCR revealed that all five $\mathrm{S} 1 \mathrm{P}$ receptors were present. The relative amount of S1P receptor mRNA was ${\mathrm{S} 1 \mathrm{P}_{2}}_{2}{\mathrm{~S} 1 \mathrm{P}_{1}>\mathrm{S}_{1} \mathrm{P}_{3}>\mathrm{S}_{1} \mathrm{P}_{4}>\mathrm{S}_{1} \mathrm{P}_{5}}$ (Fig. 4a). As $\mathrm{S} \mathrm{P}_{2}$ is the dominant $\mathrm{S} 1 \mathrm{P}$ receptor in hepatocytes, and $\mathrm{S}_{1} \mathrm{P}_{2}$ has moreover been identified as inhibiting insulin signalling in epithelial cells, the effect of S1P on insulin resistance was measured in the presence of the $\mathrm{S}_{1} \mathrm{P}_{2}$ antagonist JTE-013. S1P completely lost its ability to impair insulin-induced glucokinase production in the presence of JTE-013 (Fig. 4b). In line with this, the S1P-mediated inhibition of insulin-elicited Akt phosphorylation was diminished when the hepatocytes were preincubated with JTE-013 (Fig. 4c). These data suggest that the $\mathrm{S}_{1} \mathrm{P}_{2}$ receptor subtype is essential to crosscommunicate with insulin signalling.

\section{$\mathrm{SIP}_{2}$ antagonism improves hepatic insulin resistance in HFD-} fed NZO mice The role of $\mathrm{S}^{\mathrm{P}_{2}}$ signalling on insulin resistance was also assessed in the NZO mouse model. As expected, there was a drastic increase in blood glucose levels in HFD-fed compared with SD-fed mice over a time period of 4 weeks. Most interestingly, after treatment of HFD-fed mice with JTE-013, their glucose levels did not further increase compared with vehicle-treated HFD-fed mice (Fig. 5a). To prove whether JTE-013 mediated this action via an improvement in hepatic insulin resistance, Akt phosphorylation in the liver was measured after insulin injection. As shown, Akt phosphorylation was significantly decreased in HFD-fed compared with SD-fed mice. Treatment with JTE-013 partially restored insulin-mediated Akt phosphorylation in HFD-fed mice (Fig. 5b). Moreover, S1P determination in the liver revealed a significant increase in the sphingolipid in HFDfed compared with SD-fed mice (Fig. 5c). Conversely, $\mathrm{S}_{1} \mathrm{P}_{2}$ receptor levels in all three groups were unchanged (data not shown).

Potential relevance of S1P signalling in human hepatocytes The profile of S1P receptor subtypes was examined in primary human hepatocytes obtained from partial hepatectomy,
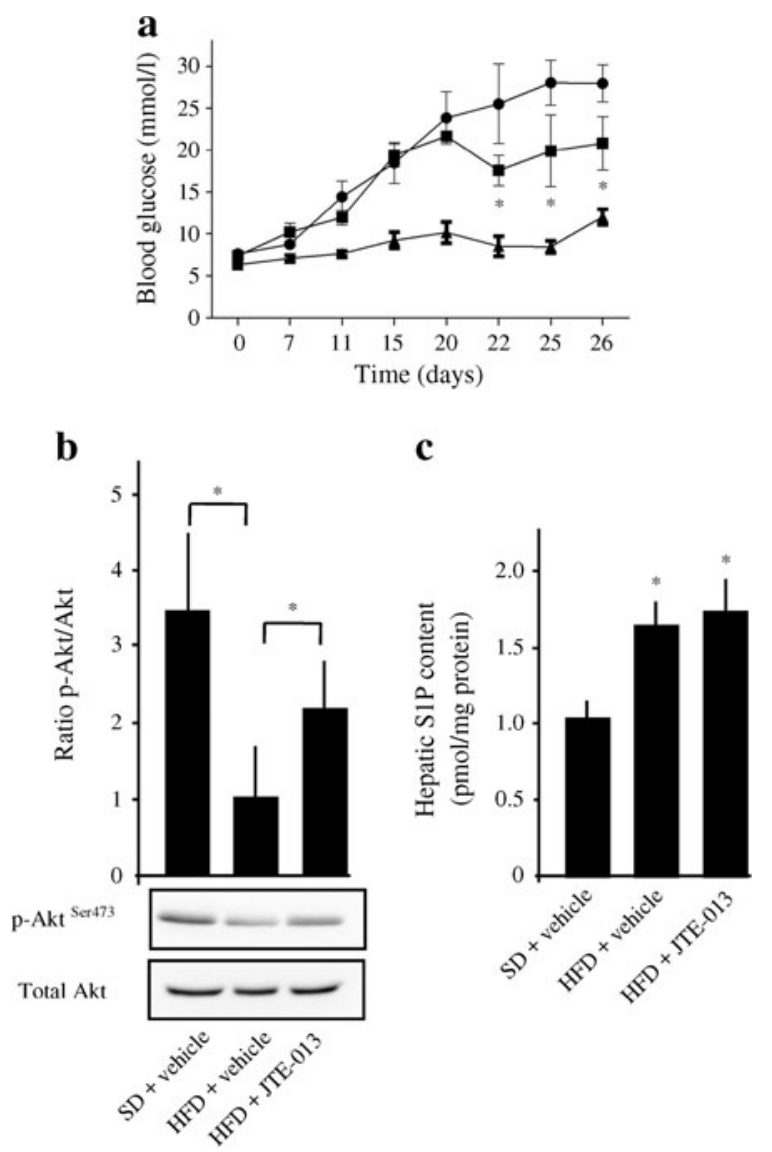

Fig. 5 Involvement of the $\mathrm{S}_{1} \mathrm{P}_{2}$ receptor subtype in hepatic insulin resistance in NZO mice. Mice were fed with SD (triangles) or HFD (squares and circles). At day 20, HFD-fed mice received $3 \mathrm{mg} / \mathrm{kg}$ JTE013 (squares) or vehicle (circles) by i.p. injection. Blood glucose was measured at the time indicated (a). After 7 days of JTE-013 treatment, mice were fasted overnight for $14 \mathrm{~h}$ followed by an i.p. injection of insulin ( $2 \mathrm{mU} / \mathrm{kg}$ ). After $15 \mathrm{~min}$, the animals were killed and the liver was harvested for measurement of phosphorylation of Akt by western blot analysis (b) and S1P content by MS/MS-QTOF analysis (c). Values are the means $\pm \operatorname{SEM}\left(n=5\right.$ for each group). ${ }^{*} p<0.05$ indicates a statistically significant difference

indicating that $\mathrm{S}_{1} \mathrm{P}_{2}$ was the most abundant receptor subtype, although all other S1P receptor subtypes were present in these cells (Fig. 6a). In analogy to rat hepatocytes, S1P formation increased in human hepatocytes in response to palmitate (Fig. 6b). Thus, S1P levels rose from approximately 12 to $20 \mathrm{pmol} / 10^{6}$ within the cells, while in the extracellular environment S1P levels increased from 5 to $10 \mathrm{pmol} / 1 \mathrm{ml}$ medium.

To examine the role of S1P in insulin signalling, $\mathrm{PI}_{3} \mathrm{~K} / \mathrm{Akt}$ phosphorylation was studied. As expected, insulin induced a pronounced activation of $\mathrm{PI}_{3} \mathrm{~K} / \mathrm{Akt}$ signalling in human hepatocytes. Importantly, pretreatment of human hepatocytes with S1P inhibited insulin-stimulated $\mathrm{PI}_{3} \mathrm{~K} /$ Akt phosphorylation (Fig. 6c, d). As in rat hepatocytes, $\mathrm{S}_{1} \mathrm{P}_{2}$ was identified as the crucial receptor subtype for inhibiting insulin-mediated 
pathways in human cells. Thus, S1P lost its ability to inhibit insulin-stimulated $\mathrm{PI}_{3} \mathrm{~K} / \mathrm{Akt}$ phosphorylation in the presence of the $\mathrm{S}_{1} \mathrm{P}_{2}$ antagonist JTE-013 (Fig. 6c). These data suggest that increased S1P levels may contribute to hepatic insulin resistance.

In this context, we studied the role in insulin signalling of the S1P receptor agonist FTY720-P, the active metabolite of the drug fingolimod approved for the treatment of multiple sclerosis. FTY720-P was not able to inhibit the insulinmediated phosphorylation of $\mathrm{PI}_{3} \mathrm{~K} / \mathrm{Akt}$ on $\mathrm{Ser}^{473}$ (Fig. 6d). This is in accordance with the fact that this immunomodulator acts on all $\mathrm{S} 1 \mathrm{P}$ receptor subtypes except $\mathrm{S}_{2} \mathrm{P}_{2}$.

\section{Discussion}

It is well established that increased plasma levels of NEFA contribute to the development of hepatic insulin resistance [2].
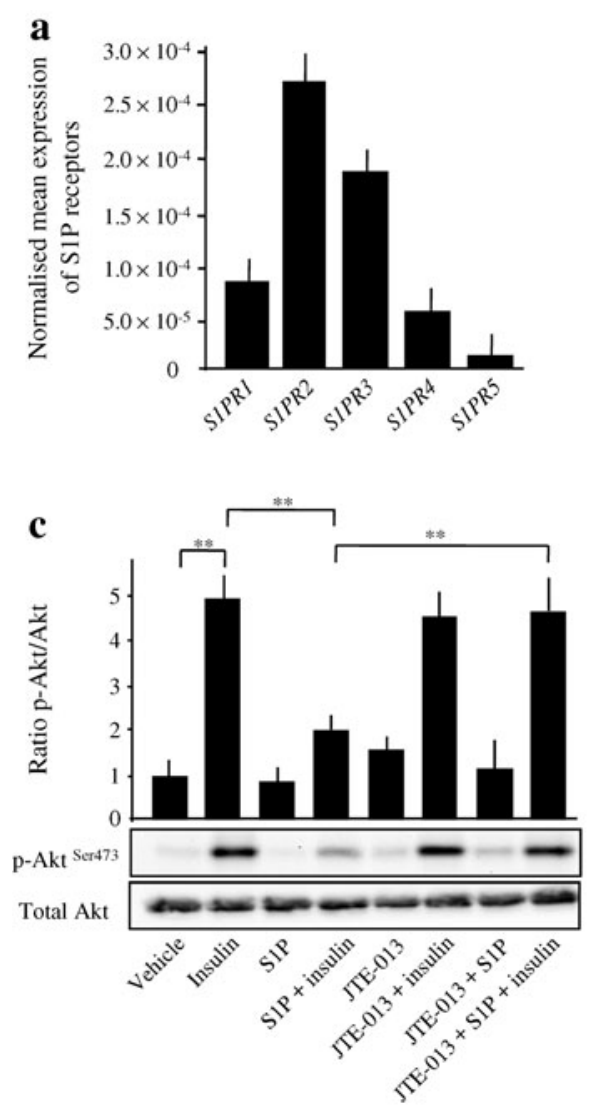

Fig. 6 Involvement of the $\mathrm{S}_{1} \mathrm{P}_{2}$ receptor subtype in $\mathrm{S} 1 \mathrm{P}$-mediated attenuation of insulin signalling in primary human hepatocytes. Quantitative real-time PCR analysis of the S1P receptor subtypes SIPR1, S1PR2, S1PR3, S1PR4 and S1PR5 was performed using beta-actin as a reference gene (a). Human hepatocytes were isolated and cultured as described. After $44 \mathrm{~h}$ of culture, cells were treated with palmitate $(0.3 \mathrm{mmol} / \mathrm{l})$ or vehicle for $12 \mathrm{~h}$. Intracellular (pmol/ $10^{6}$ cells, white bars) and extracellular (pmol/ml, black bars) S1P levels were determined by LC-MS/MSQTOF analysis (b). To inhibit $\mathrm{S}_{2}$, cells were preincubated with JTE-
Although the uptake of fatty acids into the liver is at least in part regulated by fatty acid transporters, there is a correlation between liver and plasma concentrations of fatty acids [22, 23]. The treatment of hepatocytes with NEFA such as palmitate inhibits insulin-mediated Akt phosphorylation and downstream signalling pathways including GSK-3 $\beta$ and forkhead box protein $\mathrm{O} 1$ [24]. Consequently, plasma glucose levels are increased due to an impaired stimulation of glycogen synthesis and unrestrained gluconeogenesis. Nevertheless, several studies indicate that it is not the fatty acids themselves but secondary metabolites that are responsible for the inhibitory effect on insulin signalling. Upon entry into hepatocytes, fatty acids are rapidly esterified with coenzyme A to fatty acylCoAs, which can either be shuttled into beta-oxidation or be transferred to a glycerol backbone, resulting in the formation of mono-, di- and triacylglycerols [9]. In particular, the formation of DAGs has been connected to insulin resistance [25]. Genetic studies downregulating diacylglycerol acyltransferase- 2 have indicated that a decrease in DAG
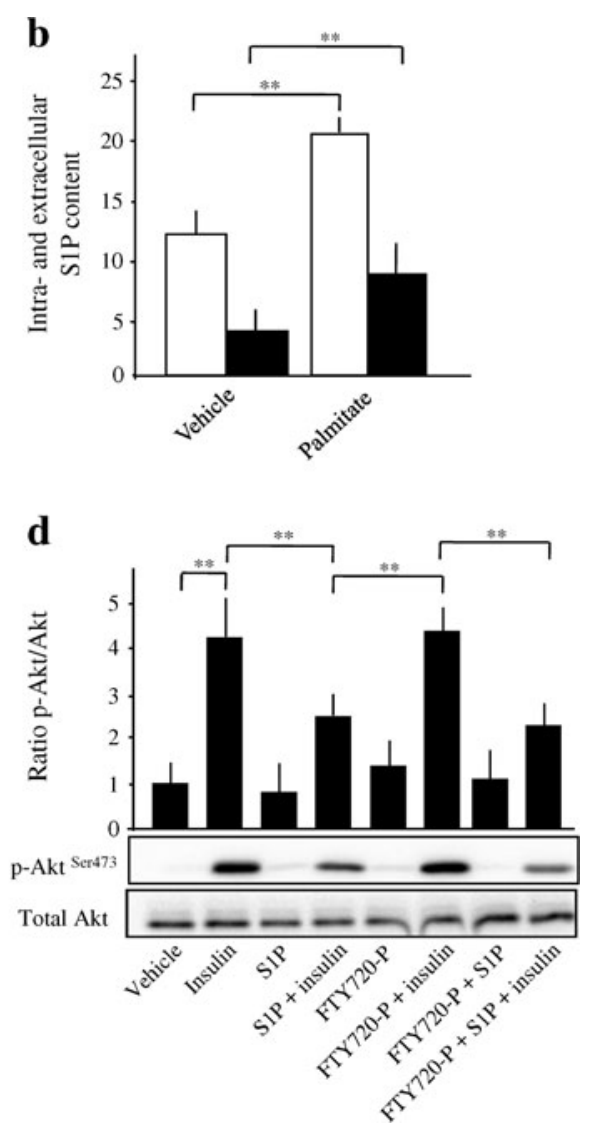

$013(10 \mu \mathrm{mol} / \mathrm{l})$ for $30 \mathrm{~min}$ followed by stimulation with vehicle or S1P $(1 \mu \mathrm{mol} / \mathrm{l})$ for $15 \mathrm{~min}$ and insulin $(10 \mathrm{nmol} / \mathrm{l})$ for $10 \mathrm{~min}(\mathbf{c})$. To examine the role of FTY720-P, cells were preincubated with vehicle, S1P $(1 \mu \mathrm{mol} / \mathrm{l})$, FTY720-P $(1 \mu \mathrm{mol} / \mathrm{l})$ or S1P + FTY720-P for $15 \mathrm{~min}$ followed by stimulation with insulin $(10 \mathrm{nmol} / \mathrm{l})$ for $10 \mathrm{~min}(\mathbf{d})$. The phosphorylation of Akt was determined by western blot analysis, with the data expressed as fold increases compared with the non-phosphorylated control. Values are the means $\pm \mathrm{SEM}$ of four independent experiments. ${ }^{* *} p<0.01$ indicates a statistically significant difference 
content is associated with improvements in insulin signalling and in vivo hepatic insulin sensitivity. DAG-mediated PKC activation has been linked to fatty liver and hepatic insulin resistance in several rodent models and in humans [26]. Thus, $\mathrm{PKC} \varepsilon$ may interrupt insulin signalling via serine/threonine phosphorylation of the insulin receptor [27].

A variety of studies indicate that saturated and unsaturated fatty acids differ in their ability to inhibit the insulin signal chain. In particular, palmitate influences insulin-mediated glucose metabolism, while this saturated fatty acid did not lead to triacylglycerol accumulation. This is in contrast to oleate, which causes an extensive triacylglycerol accumulation and does not interrupt insulin signalling but rather prevents saturated fatty acid-induced insulin resistance [28]. It is well known that the saturated fatty acid palmitate is necessary for the de novo synthesis of ceramides [29]. Several lines of evidence support a role for these sphingolipid derivatives in the pathogenesis of insulin resistance. Ceramides have been shown to activate atypical PKCs such as $\mathrm{PKC}$, , which interferes with insulin signalling [30]. In accordance with this, an inhibition of ceramide synthesis ameliorates obesity-induced hepatic insulin resistance [31]. Treating obese mice with myriocin, an inhibitor of serine palmitoyltransferase 1, specifically attenuates the increase in ceramide formation without any change in DAG level and improves glucose tolerance. In HepG2 cells, however, it has been shown that fumonisin, an inhibitor of ceramide synthases, decreases palmitate-induced ceramide levels, which was not connected with an improvement in insulin signalling [1]. Nevertheless, ceramides can be further metabolised to the bioactive sphingolipid S1P. Moreover, it is of interest that, in the presence of fumonisin,
S1P levels are enhanced, although the underlying molecular mechanism is not well defined.

It is well known that elevated plasma S1P levels are a feature of human and rodent obesity and diabetes [32, 33]. Indeed, this study clearly indicates for the first time that hepatic S1P formation is significantly increased in response to palmitate in vitro as well as in vivo. Increased levels of S1P can be detected within the cell as well as in the extracellular environment. This is in accordance with the fact that S1P can be actively transported by ATP-binding cassette (ABC) transporters, namely $\mathrm{ABCC} 1$ and $\mathrm{ABCG} 2$, in a regulated manner [21]. Thus, it is not surprising that exogenous S1P is able to inhibit insulin signalling in primary rat as well as human hepatocytes.

Depending on the cell type, it has been shown that there is a divergent crosscommunication between insulin signalling and S1P. Thus, an insulin-mimetic effect of S1P occurs in skeletal muscle as the pharmacological inhibition of Sphk1 diminishes insulin-mediated glucose uptake, while its overexpression mimics insulin action in vivo [34]. Moreover, S1P shares with insulin the ability to elicit the differentiation of myoblasts. Examination of the molecular mechanism has indicated that S1P transactivates the insulin receptor in a ligand-independent fashion [13]. Moreover, it has been shown that key enzymes of ceramide metabolism in rat muscles are modulated in response to physical activity. This is accompanied by an increased insulin sensitivity, suggesting a crucial role of sphingolipids in skeletal glucose homeostasis [35].

However, it has also been demonstrated that S1P is able to interrupt insulin signalling in epithelial cells as the bioactive sphingolipid inhibits the hormone-mediated proliferation of
Fig. 7 Hypothetical mechanism of palmitate-dependent attenuation of insulin signalling. Palmitate is metabolised to S1P, which is released into the extracellular environment. S1P binds to the $\mathrm{S}_{1} \mathrm{P}_{2}$ receptor subtype resulting in an inactivation of insulin-mediated Akt phosphorylation. This crosstalk is connected to an attenuation of glucokinase levels and GSK-3 $\beta$ activation.

Physiologically, insulin-mediated glycogen synthesis is diminished in response to S1P, suggesting that the sphingolipid mediator may contribute to hepatic insulin resistance

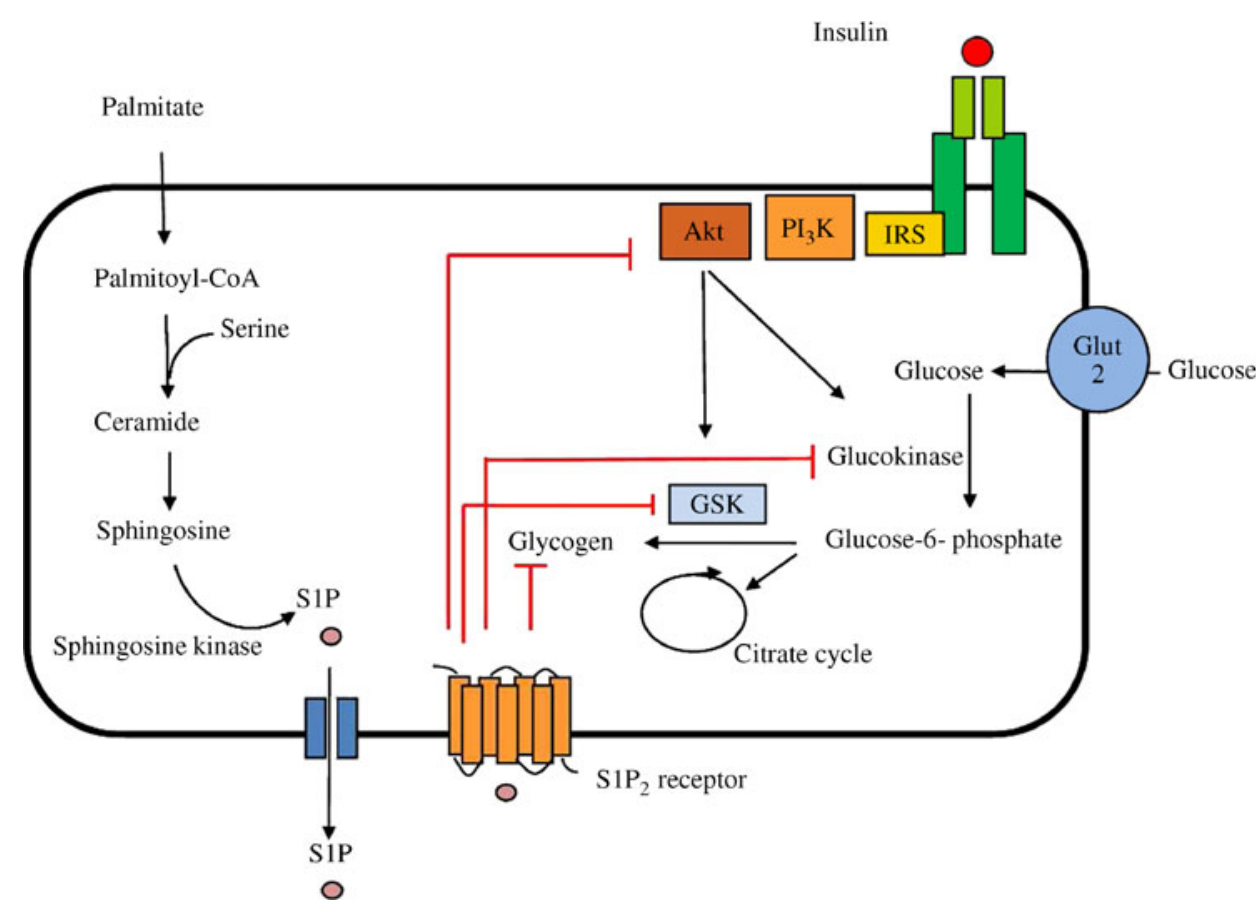


keratinocytes via stimulation of the $\mathrm{S}_{1} \mathrm{P}_{2}$ receptor subtype [14]. This is in accordance with a variety of studies indicating that $\mathrm{S}_{1} \mathrm{P}_{2}$ inhibits proliferation in several cells such as mouse embryonic fibroblasts and germinal centre $\mathrm{B}$ cells [36, 37]. The present study provides evidence that $\mathrm{S}_{1} \mathrm{P}_{2}$ stimulation is able to attenuate insulin-dependent Akt phosphorylation. Indeed, an inhibitory effect of the $\mathrm{S} 1 \mathrm{P} / \mathrm{S} \mathrm{P}_{2}$ axis on Akt activation has been identified, especially in immune cells. It has been suggested that, by inhibiting Akt activation, $\mathrm{S}_{1} \mathrm{P}_{2}$ helps to restrict germinal centre $\mathrm{B}$ cell survival and localisation to an S1P-low niche at the follicle centre [37]. Moreover, S1P has been shown to inhibit the endocytotic capacity of dendritic cells by $\mathrm{S}_{2} \mathrm{P}_{2}$ receptor activation and Akt inactivation [21]. In hepatocytes, Akt inhibition is connected with an impaired glucose utilisation and glycogen synthesis. Thus, it is not surprising that the administration of JTE-013, a specific $\mathrm{S}_{1} \mathrm{P}_{2}$ antagonist, to mice ameliorated the streptozotocin-induced blood glucose elevation and reduced the incidence of diabetes [38]. Indeed, our studies indicate that JTE-013 also diminishes the blood glucose increase in HFDfed NZO mice. In line with this, hepatic insulin signalling is improved in the presence of the $\mathrm{S}_{1} \mathrm{P}_{2}$ antagonist.

Our findings are of potential interest as FTY720, a structural analogue of sphingosine, is a potent immunosuppressant approved as a new treatment for multiple sclerosis [39]. FTY720 becomes active in vivo following phosphorylation to form FTY720-P, which binds to all S1P receptors except $\mathrm{S}_{1} \mathrm{P}_{2}$ and prevents the release of lymphocytes from lymphoid tissue. Indeed, we have indicated here that FTY720-P is not able to inhibit insulin-mediated Akt phosphorylation and glucokinase levels, confirming the essential role of $\mathrm{S}_{1} \mathrm{P}_{2}$ in insulin resistance. This is consistent with experiments indicating that the oral administration of FTY720 to $d b / d b$ mice did not lead to hyperglycaemia. In fact, diabetic mice showed a normalisation of fasting glucose levels after 6 weeks of treatment with FTY720. It has been suggested that this effect was due to a stimulation of Akt activity in beta cells [40]. This study indicates that S1P influences Akt activity in a divergent manner depending on the levels of the S1P receptor subtypes. Several lines of evidence support a role of $\mathrm{S}_{1} \mathrm{P}_{1}$ and $\mathrm{S}_{1} \mathrm{P}_{3}$ in Akt activation in response to S1P or FTY720 [41]. Measurement of the receptor profile in rat and human hepatocytes indicated a predominant expression of the $\mathrm{S}_{1} \mathrm{P}_{2}$ receptor subtype, explaining the inhibitory effect of S1P on insulinmediated Akt activation.

Taken together, our results indicate that palmitate, which is discussed as a crucial factor in the development of insulin resistance, can be metabolised by hepatocytes to S1P. This bioactive sphingolipid may act in an autocrine mechanism via stimulation of the $\mathrm{S}_{2} \mathrm{P}_{2}$ receptor to diminish insulin signalling. In particular, these findings indicate that $\mathrm{S}_{1} \mathrm{P}_{2}$ inhibition can be considered as a potential therapeutic target for insulin resistance. Therefore, the development of $\mathrm{S}_{1} \mathrm{P}_{2}$ receptor subtype-specific antagonists might be highly important for such medicinal interventions (Fig. 7).

Acknowledgements We would like to thank M. Kuna, I. Zschaler, M. Haseloff (Institute of Nutritional Science, University of Potsdam, Potsdam, Germany) and A. Mika (German Institute of Human Nutrition, Max Rubner Laboratory, Nuthetal, Germany) for their excellent technical support.

Funding This work was supported by the German Research Organization (DFG) to BK (KI-988 7-1)

Duality of interest The authors declare that there is no duality of interest associated with this manuscript.

Contribution statement All authors participated in the conception and design, or analysis and interpretation of the data, contributed to drafting and revising the manuscript, and gave final approval of the version to be published.

\section{References}

1. Lee JY, Cho HK, Kwon YH (2010) Palmitate induces insulin resistance without significant intracellular triglyceride accumulation in HepG2 cells. Metabolism 59:927-934

2. Samuel VT, Petersen KF, Shulman GI (2010) Lipid-induced insulin resistance: unravelling the mechanism. Lancet 375:2267-2277

3. Leclercq IA, Da Silva Morais A, Schroyen B, van Hul N, Geerts A (2007) Insulin resistance in hepatocytes and sinusoidal liver cells: mechanisms and consequences. J Hepatol 47:142-156

4. Cross DA, Alessi DR, Cohen P, Andjelkovich M, Hemmings BA (1995) Inhibition of glycogen synthase kinase-3 by insulin mediated by protein kinase B. Nature 378:785-789

5. Hagiwara A, Cornu M, Cybulski N et al (2012) Hepatic mTORC2 activates glycolysis and lipogenesis through Akt, glucokinase, and SREBP1c. Cell Metab 15:725-738

6. Cai D, Yuan M, Frantz DF et al (2005) Local and systemic insulin resistance resulting from hepatic activation of IKK-beta and NFkappaB. Nat Med 11:183-190

7. Jornayvaz FR, Shulman GI (2012) Diacylglycerol activation of protein kinase $\mathrm{C}$ epsilon and hepatic insulin resistance. Cell Metab 15:574-584

8. Listenberger LL, Han X, Lewis SE et al (2003) Triglyceride accumulation protects against fatty acid-induced lipotoxicity. Proc Natl Acad Sci U S A 100:3077-3082

9. Samuel VT, Shulman GI (2012) Mechanisms for insulin resistance: common threads and missing links. Cell 148:852-871

10. Powell DJ, Hajduch E, Kular G, Hundal HS (2003) Ceramide disables 3-phosphoinositide binding to the pleckstrin homology domain of protein kinase B (PKB)/Akt by a PKCzeta-dependent mechanism. Mol Cell Biol 23:7794-7808

11. Kihara A, Anada Y, Igarashi Y (2006) Mouse sphingosine kinase isoforms SPHK1a and SPHK1b differ in enzymatic traits including stability, localization, modification, and oligomerization. J Biol Chem 281:4532-4539

12. Chun J, Goetzl EJ, Hla T et al (2002) International Union of Pharmacology. XXXIV. Lysophospholipid receptor nomenclature. Pharmacol Rev 54:265-269

13. Rapizzi E, Taddei ML, Fiaschi T, Donati C, Bruni P, Chiarugi $P$ (2009) Sphingosine 1-phosphate increases glucose uptake through trans-activation of insulin receptor. Cell Mol Life Sci 66:3207-3218 
14. Schüppel M, Kürschner U, Kleuser U, Schäfer-Korting M, Kleuser B (2008) Sphingosine 1-phosphate restrains insulin-mediated keratinocyte proliferation via inhibition of Akt through the S1P2 receptor subtype. J Invest Dermatol 128:1747-1756

15. Blot V, Jacquemard U, Reissig HU, Kleuser B (2009) Practical syntheses of sphingosine-1-phosphate and analogues. Synthesis 5:759-766

16. Hespeling U, Jungermann K, Püschel GP (1995) Feedback-inhibition of glucagon-stimulated glycogenolysis in hepatocyte/Kupffer cell cocultures by glucagon-elicited prostaglandin production in Kupffer cells. Hepatology 22:1577-1583

17. Henkel J, Neuschäfer-Rube F, Pathe-Neuschäfer-Rube A, Püschel GP (2009) Aggravation by prostaglandin E2 of interleukin-6-dependent insulin resistance in hepatocytes. Hepatology 50:781-790

18. Knobeloch D, Ehnert S, Schyschka L et al (2012) Human hepatocytes: isolation, culture, and quality procedures. Methods Mol Biol 806:99-120

19. Lotinun S, Kiviranta R, Matsubara T et al (2013) Osteoclast-specific cathepsin $\mathrm{K}$ deletion stimulates S1P-dependent bone formation. J Clin Invest 123:666-681

20. Gulbins E, Palmada M, Reichel M et al (2013) Acid sphingomyelinaseceramide system mediates effects of antidepressant drugs. Nat Med 19: 934-938

21. Japtok L, Schaper K, Bäumer W, Radeke HH, Jeong SK, Kleuser B (2012) Sphingosine 1-phosphate modulates antigen capture by murine Langerhans cells via the S1P2 receptor subtype. PLoS One 7:e49427

22. Bradbury MW (2006) Lipid metabolism and liver inflammation. I. Hepatic fatty acid uptake: possible role in steatosis. Am J Physiol Gastrointest Liver Physiol 290:G194-G198

23. Chabowski A, Zendzian-Piotrowska M, Konstantynowicz K et al (2013) Fatty acid transporters involved in the palmitate and oleate induced insulin resistance in primary rat hepatocytes. Acta Physiol (Oxf) 207:346-357

24. Puigserver P, Rhee J, Donovan J et al (2003) Insulin-regulated hepatic gluconeogenesis through FOXO1-PGC-1alpha interaction. Nature 423:550-555

25. Neschen S, Morino K, Hammond LE et al (2005) Prevention of hepatic steatosis and hepatic insulin resistance in mitochondrial acyl-CoA:glycerol-sn-3-phosphate acyltransferase 1 knockout mice. Cell Metab 2:55-65

26. Samuel VT, Liu ZX, Qu X et al (2004) Mechanism of hepatic insulin resistance in non-alcoholic fatty liver disease. J Biol Chem 279:32345-32353

27. Samuel VT, Liu ZX, Wang A et al (2007) Inhibition of protein kinase $\mathrm{C}$ epsilon prevents hepatic insulin resistance in nonalcoholic fatty liver disease. J Clin Invest 117:739-745
28. Salvado L, Coll T, Gomez-Foix AM et al (2013) Oleate prevents saturated-fatty-acid-induced ER stress, inflammation and insulin resistance in skeletal muscle cells through an AMPK-dependent mechanism. Diabetologia 56:1372-1382

29. Ussher JR, Koves TR, Cadete VJ et al (2010) Inhibition of de novo ceramide synthesis reverses diet-induced insulin resistance and enhances whole-body oxygen consumption. Diabetes 59:2453-2464

30. Powell DJ, Turban S, Gray A, Hajduch E, Hundal HS (2004) Intracellular ceramide synthesis and protein kinase $\mathrm{C}$ zeta activation play an essential role in palmitate-induced insulin resistance in rat L6 skeletal muscle cells. Biochem J 382:619-629

31. Holland WL, Brozinick JT, Wang LP et al (2007) Inhibition of ceramide synthesis ameliorates glucocorticoid-, saturated-fat-, and obesity-induced insulin resistance. Cell Metab 5:167-179

32. Kowalski GM, Carey AL, Selathurai A, Kingwell BA, Bruce CR (2013) Plasma sphingosine-1-phosphate is elevated in obesity. PLoS One 8:e72449

33. Fox TE, Bewley MC, Unrath KA et al (2011) Circulating sphingolipid biomarkers in models of type 1 diabetes. J Lipid Res 52:509-517

34. Ma MM, Chen JL, Wang GG et al (2007) Sphingosine kinase 1 participates in insulin signalling and regulates glucose metabolism and homeostasis in KK/Ay diabetic mice. Diabetologia 50:891-900

35. Blachnio-Zabielska A, Zabielski P, Baranowski M, Gorski J (2011) Aerobic training in rats increases skeletal muscle sphingomyelinase and serine palmitoyltransferase activity, while decreasing ceramidase activity. Lipids 46:229-238

36. Goparaju SK, Jolly PS, Watterson KR et al (2005) The S1P2 receptor negatively regulates platelet-derived growth factor-induced motility and proliferation. Mol Cell Biol 25:4237-4249

37. Green JA, Suzuki K, Cho B et al (2011) The sphingosine 1-phosphate receptor S1P(2) maintains the homeostasis of germinal center B cells and promotes niche confinement. Nat Immunol 12:672-680

38. Imasawa T, Koike K, Ishii I, Chun J, Yatomi Y (2010) Blockade of sphingosine 1-phosphate receptor 2 signaling attenuates streptozotocin-induced apoptosis of pancreatic beta-cells. Biochem Biophys Res Commun 392:207-211

39. Brinkmann V, Billich A, Baumruker T et al (2010) Fingolimod (FTY720): discovery and development of an oral drug to treat multiple sclerosis. Nat Rev Drug Discov 9:883-897

40. Zhao Z, Choi J, Zhao C, Ma ZA (2012) FTY720 normalizes hyperglycemia by stimulating beta-cell in vivo regeneration in $d b / d b$ mice through regulation of cyclin D3 and p57(KIP2). J Biol Chem 287:5562-5573

41. Egom EE, Mohamed TM, Mamas MA et al (2011) Activation of Pak1/Akt/eNOS signaling following sphingosine-1-phosphate release as part of a mechanism protecting cardiomyocytes against ischemic cell injury. Am J Physiol Heart Circ Physiol 301:H1487-H1495 